\title{
Production of Pectin-Cellulose Biofilms: A New Approach for Citrus Waste Recycling
}

\author{
Veronika Bátori, Mostafa Jabbari, Dan Åkesson, Patrik R. Lennartsson, \\ Mohammad J. Taherzadeh, and Akram Zamani
}

\author{
Swedish Centre for Resource Recovery, University of Borås, 50190 Borås, Sweden \\ Correspondence should be addressed to Veronika Bátori; veronika.batori@hb.se
}

Received 24 July 2017; Revised 23 September 2017; Accepted 28 September 2017; Published 29 October 2017

Academic Editor: Arthur J. Ragauskas

Copyright (c) 2017 Veronika Bátori et al. This is an open access article distributed under the Creative Commons Attribution License, which permits unrestricted use, distribution, and reproduction in any medium, provided the original work is properly cited.

\begin{abstract}
While citrus waste is abundantly generated, the disposal methods used today remain unsatisfactory: they can be deleterious for ruminants, can cause soil salinity, or are not economically feasible; yet citrus waste consists of various valuable polymers. This paper introduces a novel environmentally safe approach that utilizes citrus waste polymers as a biobased and biodegradable film, for example, for food packaging. Orange waste has been investigated for biofilm production, using the gelling ability of pectin and the strength of cellulosic fibres. A casting method was used to form a film from the previously washed, dried, and milled orange waste. Two film-drying methods, a laboratory oven and an incubator shaker, were compared. FE-SEM images confirmed a smoother film morphology when the incubator shaker was used for drying. The tensile strength of the films was $31.67 \pm 4.21$ and $34.76 \pm 2.64 \mathrm{MPa}$, respectively, for the oven-dried and incubator-dried films, which is within the range of different commodity plastics. Additionally, biodegradability of the films was confirmed under anaerobic conditions. Films showed an opaque appearance with yellowish colour.
\end{abstract}

\section{Introduction}

Plastics production has increased enormously in the past 100 years, and a global production of 322 million tons was reported by Statista [1] for 2015. This vast number of plastic products caused severe plastic pollution by now and they are typically made from nonrenewable sources. On the contrary, bioplastics are made from renewable sources or they are biodegradable; in the best-case scenario, they are both. Today, biopolymers are produced from cultivated crops; however, the land used for bioplastic is still negligible [2]

An example for a biobased and biodegradable material that is built up of different biopolymers, with no land use, is citrus waste. Citrus waste is a globally abundant and environmentally challenging waste that is underutilized [3]. Among citrus fruits, sweet oranges are the most commonly grown tropical fruits worldwide [4]. USDA [5] forecasted 45.8 million tons of sweet orange production for 2015/16. Industrial orange processing, for example, orange juice production generates about $50-60 \%$ residue of the original mass of the orange [6]. This vast quantity of waste is high in organic matter content (approx. 95\% of total solids) and water (approx. 80-90\%) and has a low pH (3-4) and inappropriate handling could cause severe damage to the environment [6]. Orange waste also contains pectin, soluble sugars, hemicelluloses, cellulose, starch, protein, lignin, ash, fat, and flavonoids $[7,8]$, which have been shown to be beneficial to many yet imperfect disposal and recovery applications [6]. These compounds on the other hand could be interesting for bioplastics applications.

Orange waste has already been applied as a reinforcement in petrochemical or biobased matrices [9-11]. In all of these cases, the authors reported increased mechanical properties of the products compared to the neat polymer. The increased mechanical properties are most probably the direct effect of the present cellulosic fibres. However, pectin, the major component of orange peel, seems to have no significant effect in the above-mentioned composites. Nevertheless, pectin-based composites have been prepared with different reinforcing substances [12] and cellulosic plant fibres have 
certainly been of great interest because of their favourable mechanical properties as a potential substitute for glass fibres [13] in biocomposites. Cellulose reinforced pectin composites have been developed, for example, for tissue engineering applications [14] and for food packaging applications [15] from commercial sources. However, there is no study on directly using cellulosic fibres and pectin obtained from citrus waste to prepare a biofilm.

This study investigated transforming orange waste into a biobased film as well as evaluating its properties. As a result of our study, a new function was given to orange waste and biofilms were developed without prior chemical modification of the raw material. Films were prepared with a filmcasting method. The orange waste film (OWF) is plant-based and biodegradable and represents competitive mechanical properties with some of the commodity plastics. Therefore, with further improvements, OWF could be potentially used for nonstructural applications, for example, as a sustainable packaging material for the food industry.

\section{Materials and Methods}

2.1. Materials. Orange waste (OW) was obtained from Brämhults Juice $\mathrm{AB}$ (Borås, Sweden). Until further processing, the $\mathrm{OW}$ was stored at $-20^{\circ} \mathrm{C}$. Citric acid (monohydrate, $>99.5 \%$, Duchefa Biochemie, Netherlands), glycerol (>99\%, ARCOS Organics, Belgium), organic antifoam 204 (Sigma-Aldrich, USA), and pectins (P9311, P9436, and P9561, Sigma-Aldrich, USA) were other materials used in this study.

2.2. Pretreatment of Orange Waste for Film Preparation. OW was washed with water to extract soluble sugars. Firstly, the material was soaked in tap water overnight; then, two further washing steps followed. The water $(\mathrm{L})$ to $\mathrm{OW}(\mathrm{kg})$ ratio for all steps was $1.5: 1$. Each washing included shaking the $\mathrm{OW}$ in a water bath at $115 \mathrm{rpm}$ for $20 \mathrm{~min}$ at $35^{\circ} \mathrm{C}$. After each washing, the OW was collected from the flask using a metal sieve and rinsed under tap water. Size of the washed OW particles was reduced with a knife and they were dried for $16 \mathrm{~h}$ at $40^{\circ} \mathrm{C}$. Dried OW was milled to a fine powder using a ball mill (Retsch MM 400, Germany) at a frequency of $30 \mathrm{~Hz}$, for a total of $40 \mathrm{~min}$, allowing the equipment to cool down after each 10 min milling (preliminary tests were also performed for 10,20 , and $30 \mathrm{~min}$ ).

2.3. Formation of Orange Waste Films. A mixture of $2 \%(\mathrm{w} / \mathrm{v})$ of OW powder was prepared in $1 \%(\mathrm{w} / \mathrm{v})$ citric acid solution under constant magnetic stirring while heating up to $70^{\circ} \mathrm{C}$. The acid solution also contained 7\% (w/w) glycerol and 1 drop of organic antifoam $/ 100 \mathrm{~mL}$ solution. The suspension was sieved through a metal sieve to eliminate nascent air bubbles before it was poured onto PTFE plates and dried at $40^{\circ} \mathrm{C}$. Each plate contained $30 \mathrm{~g}$ of suspension and the diameter of the plates was $100 \mathrm{~mm}$. The drying process was performed in either a laboratory drying oven (Termaks TS9026, Norway) or an incubator shaker (New Brunswick ${ }^{\mathrm{TM}}$ Scientific Excella ${ }^{\circledR}$ E24, USA) rotating at $50 \mathrm{rpm}$. In the following, films dried in the oven are referred to as oven-dried (OD) and in the incubator as incubator-dried (ID). Properties of OD and ID films were compared in the study.

2.4. Characterization of Orange Waste and Biofilms. Soluble sugars were removed from the orange waste before any compositional analyses.

2.4.1. Dry and Moisture Contents. Dry content of wet OW and moisture content of dry OW powder were determined by drying the samples at $105^{\circ} \mathrm{C}$ until constant weight. Tests were performed in duplicate.

2.4.2. Carbohydrate Content. Structural carbohydrate content of the OW powder was determined according to NREL/TP-510-42618 [17] via hydrolysis with hot sulphuric acid. The different carbohydrate fractions were identified and quantified by high-performance liquid chromatography (HPLC) (Waters 2695, Waters, Milford, USA), using a lead(II)-based column (HPX-87P, BioRad) with two MicroGuard Deashing (Bio-Rad) precolumns operated at $85^{\circ} \mathrm{C}$ with $0.6 \mathrm{~mL} / \mathrm{min}$ ultrapure water as eluent.

2.4.3. Pectin Content. Pectin content of the OW was measured by extraction. Pectin was extracted using a laboratory scale high-performance microwave digestion system (Milestone Ethos UP MA182, Italy). Size-reduced OW (20 g) was mixed with $45 \mathrm{~mL}$ of acidified water $(25 \mathrm{~mL}$ of distilled water and $25 \mathrm{~mL}$ of $0.1 \mathrm{M} \mathrm{HNO}_{3}$ ) to gain $\mathrm{pH} 2$ [4]. The mixture was transferred into a PTFE vial with a total volume of $100 \mathrm{~mL}$ and was treated at $120^{\circ} \mathrm{C}$ for $10 \mathrm{~min}$ at a maximum power of $500 \mathrm{~W}$. The treatment followed a $10 \mathrm{~min}$ ramping while the mixture was continuously stirred with a magnet stirrer. After the extraction, the mixture was cooled to room temperature and the solids were separated using vacuum filtration through a grade 3 filter paper. Pectin precipitation was performed according to Srivastava and Malviya [18] with slight modifications. The filtrate was adjusted to $\mathrm{pH}$ 4.5 [4] with $2 \mathrm{M}$ of $\mathrm{NaOH}$ and cooled to $4^{\circ} \mathrm{C}$ before it was precipitated with ethanol under continuous stirring for $15 \mathrm{~min}$. Ethanol to filtrate ratio was $2: 1$. The mixture was kept at $4^{\circ} \mathrm{C}$ for another 2 hours to allow pectin floatation, before being filtered through a cheesecloth to collect the extracted pectin. The pectin was then washed with absolute ethanol and dried to constant weight at $40^{\circ} \mathrm{C}$.

2.4.4. Degree of Esterification of Pectin. A Fourier transform infrared (FTIR) spectrometer (Thermo Scientific, Nicolet iS10, USA) was used to measure the degree of esterification (DE) of the isolated pectin. Nicolet OMNIC 4.1 software was used to generate spectral data, which were analysed by Essential FTIR ${ }^{\circledR}$ (eFTIR, USA) software. The analysis was performed according to Oliveira et al. [19] with some modifications. Pectins with known values of DE $(27 \pm 7 \%, 62.5 \pm$ $7.5 \%$, and $\geq 85 \%$ ) were used as standard. Determination of DE was based on the band areas at $1700-1750 \mathrm{~cm}^{-1}$, corresponding to methyl esterified galacturonic acids (EGA), and at $1600-1630 \mathrm{~cm}^{-1}$, corresponding to the free galacturonic acids 
(FGA), and calculated according to the equation obtained from the calibration curve after plotting the standard values:

$$
\begin{aligned}
\mathrm{DE} & =75.308 R_{A}+29.923, \\
R^{2} & =0.9588 \\
R_{A} & =\frac{A_{\mathrm{EGA}}}{A_{\mathrm{EGA}}+A_{\mathrm{FGA}}}
\end{aligned}
$$

2.4.5. Morphology. The morphology of film surface and transversal sections was investigated by FE-SEM imaging (Zeiss, Sigma, Germany). For surface visualisation, films were attached to a carbon tape and covered with gold. For transverse visualisation, images of cross section of the films were also taken. Each film was immersed in liquid nitrogen for one minute; then it was broken and immediately attached to a carbon tape on a stub. Following that, the samples were coated with gold and images were taken. Photomicrographs were taken at 1000 magnifications, using an accelerating voltage of 10 and $25 \mathrm{kV}$.

2.4.6. Mechanical Testing. A tensile test was performed according to ISO 527, using Tinius Olsen H10KT universal tester and QMat software package. A moving cross-head was used to pull the dumbbell shaped specimens apart with a load cell of $250 \mathrm{~N}$ and a test speed of $10 \mathrm{~mm} / \mathrm{min}$. Specimens with a gauge length of $22 \mathrm{~mm}$ and a width of $4 \mathrm{~mm}$ were tested in triplicate and the averages are reported as tensile strength (MPa), elongation at break (\%), and elongation at maximum tensile strength (\%).

2.4.7. Thermal Analyses. Thermogravimetric analysis (TGA) (Q500 TA instruments, Waters LLC, USA) was performed to determine chemical film properties, such as decomposition. Approximately 6 to $8 \mathrm{mg}$ of each sample was heated from room temperature to $700^{\circ} \mathrm{C}$ at a rate of $10^{\circ} \mathrm{C} / \mathrm{min}$. The analysis was performed under nitrogen atmosphere. Tests were done in triplicate, and an average is reported.

A differential scanning calorimetry (DSC) analysis (Q2000 TA Instruments, Waters LLC, USA) was performed to determine thermal properties. Approximately 6 to $8 \mathrm{mg}$ of the biofilm sample was heated in an aluminium pan from -20 to $200^{\circ} \mathrm{C}$ at a rate of $10^{\circ} \mathrm{C} / \mathrm{min}$ in the first scan and in the rescanning. The analysis was done under nitrogen atmosphere. Tests were done in triplicate and an average is reported.

A dynamic mechanical thermal analysis (DMTA) (Q800, TA Instruments, Waters LLC, USA) was performed to determine dynamic mechanical properties, operated in a multifrequency strain mode, using a tension film clamp. The samples were cut in a typical width of $5.3 \mathrm{~mm}$ by a length of 8 to $9 \mathrm{~mm}$ and examined at a heat rating of $3^{\circ} \mathrm{C} / \mathrm{min}$ from 0 to $140^{\circ} \mathrm{C}$, at a strain frequency of $1 \mathrm{~Hz}$, and at amplitude of $15 \mu \mathrm{m}$. Tests were done in triplicate.

2.4.8. Antimicrobial Test. The antimicrobial activity of the films was investigated by cultivating Escherichia coli (ATTC 25922, received from Södra Älvsborgs Sjukhus Borås, Sweden), a food-related and easily growing bacteria, and
Aspergillus oryzae (CBS 819.72, Centraalbureau voor Schimmelcultures, Netherlands), a type of mould, in $250 \mathrm{~mL}$ Erlenmeyer-flasks. The cultivation flasks contained $50 \mathrm{~mL} \mathrm{LB}$ (10 g/L tryptone, $5 \mathrm{~g} / \mathrm{L}$ yeast extract, $10 \mathrm{~g} / \mathrm{L} \mathrm{NaCl})$ and YPD (10 g/L yeast extract, $20 \mathrm{~g} / \mathrm{L}$ peptone, $20 \mathrm{~g} / \mathrm{L}$ glucose) broth, as well as $5 \mathrm{~mL}$ phosphate buffer ( $\mathrm{pH} 7)$ to maintain the optimum $\mathrm{pH}$ for the mentioned microorganisms, respectively. A sample of $0.50 \mathrm{~g}$ of the film was added to each flask, except for the reference flask that contained only the microorganism. The test was carried out in duplicate for 24 and 36 hours, respectively, in an incubator shaker at $125 \mathrm{rpm}$ and $30^{\circ} \mathrm{C}$. LB broth was inoculated with one colony, using an inoculation loop obtained from previously grown agar plates. YPD broth was inoculated with $3 \mathrm{~mL}$ spore solution of $5.41 \times 10^{5}$ spores $/ \mathrm{mL}$ obtained from previously grown agar plates. Bacterial growth was determined by measuring the optical density value of the broth with a spectrophotometer (Biochrom, WPA Spectrawave S1200 Diode Array Spectrophotometer, UK) at a wavelength of $600 \mathrm{~nm}$. Fungal growth was determined by measuring the sugar consumption in the broth with HPLC.

2.4.9. Biodegradability Test. Anaerobic digestion was performed in order to test the biodegradation of the films. Digestion was carried out in batch reactors according to a previous study [21]. Bacterial inoculum was obtained from a large-scale thermophilic biogas plant (Borås Energi \& Miljö $\mathrm{AB}$, Borås, Sweden). Total solids (TS) content and volatile solids (VS) content of the films were determined using a gravimetric method. Each $120 \mathrm{~mL}$ glass bottle of a working volume of $50 \mathrm{~mL}$ contained $35.5 \mathrm{~mL}$ inoculum, and the rest was water. Each bottle contained $0.15 \mathrm{~g}$ sample VS. The reactors were then flushed with a gas mixture consisting of $80 \% \mathrm{~N}_{2}$ and $20 \% \mathrm{CO}_{2}$ for $2 \mathrm{~min}$. The reactors were incubated for 30 days at $55^{\circ} \mathrm{C}$. Reactors containing only water and inoculum were used as blanks, and pure cellulose (Avicel ${ }^{\circledR}$, Sigma-Aldrich) was also used as a reference. The experiment was performed in triplicate. $0.2 \mathrm{~mL}$ gas samples were taken with a $0.25 \mathrm{~mL}$ syringe (VICI, USA). The gas composition was analysed using a gas chromatograph (Clarus 500, PerkinElmer, USA) equipped with a packed column (Perkin-Elmer, $6^{\prime} \times 1.8^{\prime \prime} \mathrm{OD}, 80 / 100$, Mesh, USA) and a thermal conductivity detector (Perkin-Elmer, USA) with an injection temperature of $150^{\circ} \mathrm{C}$. The carrier gas was nitrogen, and the equipment was operated at a $20 \mathrm{~mL} / \mathrm{min}$ flow rate at $60^{\circ} \mathrm{C}$. At the end of the digestion, the $\mathrm{pH}$ of the digestates was also measured.

2.4.10. Statistical Analysis. Statistical analysis of the data obtained from mechanical and thermal tests was performed using MINITAB 17 Statistical Software. Results were compared by obtaining a $p$ value via $t$-test, with a $95 \%$ confidence interval.

\section{Results and Discussion}

The results of the compositional analyses of orange waste are summarized in Table 1. Although values depend on the source and on the conditions of treatment and isolation methods, the major component of OW is pectin, followed by 
TABLE 1: Chemical composition of OW according to the literature [20] and the results obtained from material characterization (\% $($ w/dry w)).

\begin{tabular}{lcc}
\hline Compound/content & {$[20](\%)$} & Characterization (\%) \\
\hline Pectin & 42.5 & $29.84 \pm 0.29$ \\
Cellulose & 9.2 & $18.66 \pm 0.48$ \\
Hemicelluloses & 10.5 & $20.89 \pm 0.89$ \\
Soluble sugars & 16.9 & \\
Protein & 6.5 & \\
Lignin & 0.8 & \\
Fat & 2.0 & \\
Ash & 3.5 & \\
Starch & 3.8 & \\
Others & 4.4 & about 30 \\
DE of pectin & & $42.72 \pm 1.10$ \\
Dry matter of OW & & $9.84 \pm 1.21$ \\
Moisture content of OW powder & & $9.58 \pm 0.03$ \\
\hline
\end{tabular}

hemicellulose and cellulose. In this study, pectin, cellulose, and hemicellulose fibres gained main focus for biofilm preparation. Biofilms from OW were produced by the direct conversion of orange waste (Figure 1) with no prior chemical treatment of the waste. The physical and thermal properties of the films are influenced by both the cellulose and hemicelluloses fractions and the surrounding pectin phase. This new approach could be a solution to the problems associated with orange waste handling.

3.1. Details of the Method for Production of Biofilms from Orange Waste. Soluble sugars were removed from the OW during the pretreatment steps because preliminary experiments showed that when the sugars were not removed, the film surface was heterogeneous and cracked. To obtain a homogeneous OW powder to result in the most compatible film structure, different milling times (10, 20,30, and $40 \mathrm{~min})$ were tested. 40 min milling showed satisfactory results based on visual observation. Particle sizes were mostly between 125 and $75 \mu \mathrm{m}$. Since particle size could not be controlled with ball milling, a variety of the sizes were present in the OW powder.

Films were prepared by a casting method in which cellulose and hemicelluloses fibres were suspended in the pectin solution and further dried to a film. The orientation of the cellulosic fibres in the films could not be aligned and therefore, the particles were randomly distributed. Pectin film formation as well as previous studies on OWF formation showed that pectin forms foam on the surface of the mixture (data not shown); therefore, organic antifoam was added to the solvent liquid. Initial investigations on drying at 30, 40, and $50^{\circ} \mathrm{C}$ as well as at room temperature were performed. Drying temperature for solvent evaporation seemed not to be sufficient when films were dried at room temperature or at $30^{\circ} \mathrm{C}$. When $50^{\circ} \mathrm{C}$ was applied, cracks were formed in the films. The higher temperature resulted in faster evaporation of the solvent at the edges of the film, thus creating a presumably more intensive replacement of liquid from the

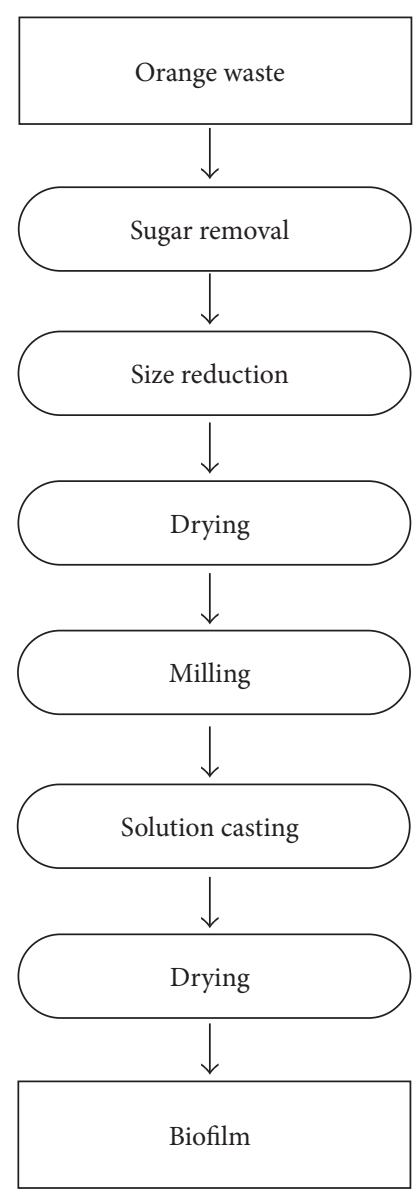

FIGURE 1: Flow chart of the developed method for production of orange waste films.

centre towards the edges, as explained by Routh [22]. In order to reduce the liquid flow in which the dispersed particles could be carried towards the edges (coffee-ring effect) [22], the temperature was reduced to obtain a slower evaporation of the solvent. Oven drying at $40^{\circ} \mathrm{C}$ resulted in no cracks, only a few small holes in the films were visible, and about 7 hours were enough for complete drying. Once the temperature was optimized, another drying method was also evaluated to eliminate the holes. An incubator shaker was then used to provide continuously rotating movements. The continuous movement of liquid and particles avoided the so-called coffee-ring effect as explained above. As a result, ID films without holes were produced, though the thickness of those films was uneven. The thickness of OD films was $0.09-0.10 \mathrm{~mm}$, while ID films were more irregular. For mechanical characterization, the most uniform part of the ID films was chosen $(0.08-0.10 \mathrm{~mm})$, and the average thickness was used for analysis. By appearances, the biofilms are opaque and have a yellowish colour. The method for production of biofilms from orange waste is schematically presented in Figure 1.

3.2. Morphology of Orange Waste Films. The FE-SEM images shown on Figure 2 reveal that a "second layer" (highlighted 


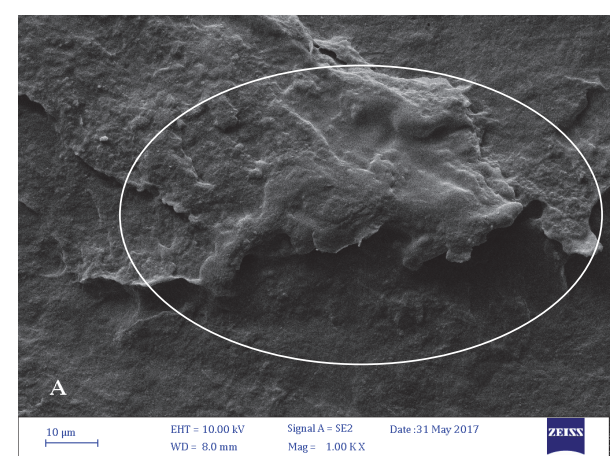

(a)

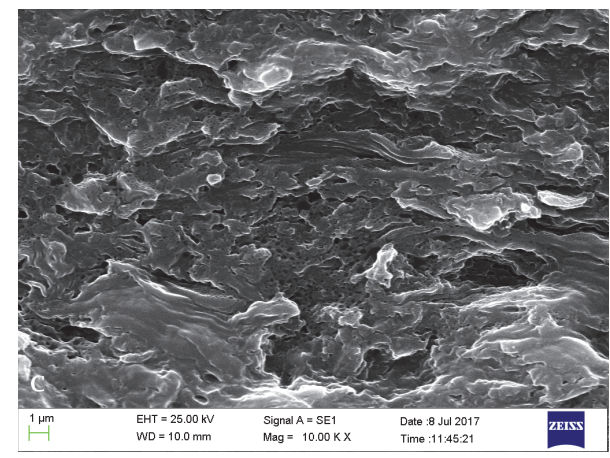

(c)

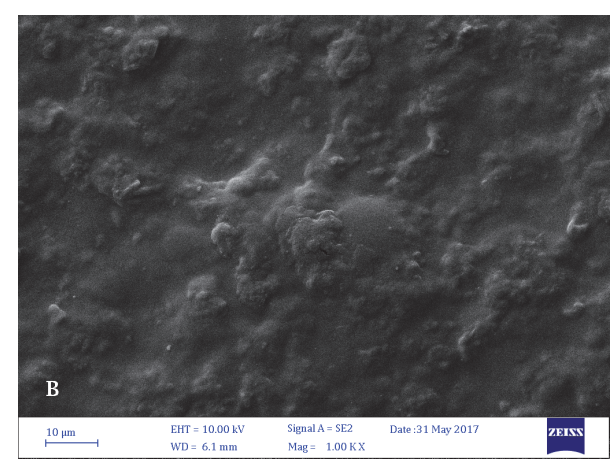

(b)

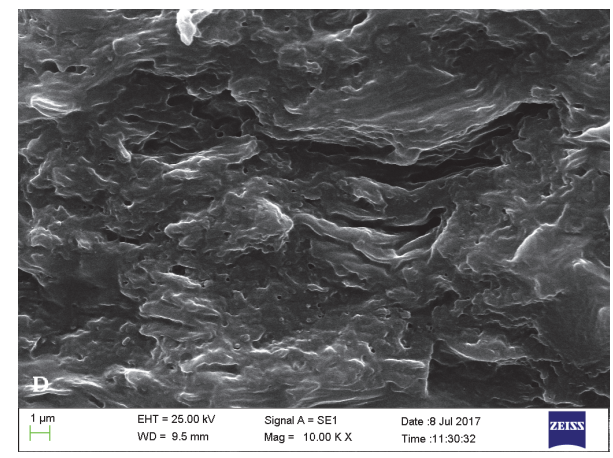

(d)

FIGURE 2: FE-SEM images taken from surface of OD (a) and ID (b) films and from transversal sections of OD (c) and ID (d) films. On image (a) a circle is highlighting the unevenness of the surface compared to the more uniform surface shown on image (b).

on the image) was formed on the surface of OD films. In drying films, where there are more than one type of particles, a common phenomenon is self-stratification, which means that one particle ends on top of another [22]. As OWFs are made of a complex mixture of dissolved and undissolved polymers this phenomenon under the "normal" drying conditions seems to occur. When the "normal" drying conditions were disturbed with continuous rotation, this phenomenon was not visible; instead it resulted in a smooth and uniform surface of the ID films. The transversal sections confirm that continuous rotation resulted in a more homogenous material: pores are visible in the structure of OD films, while there are no clear pores in ID films. The few voids that can be seen could be the result of pulling the cellulosic fibres out during fractioning. Since there was no alignment of the fibres, the magnitude of these voids is low.

3.3. Mechanical Analysis of Orange Waste Films. Tensile strengths of the OWFs produced in this study were measured between 28 and $36 \mathrm{MPa}$ (Figure 3). Yu et al. [15] varied the ratio between LM pectin and CMC to prepare nanocomposites by adding up to $8 \% \mathrm{w} / \mathrm{w}$ of montmorillonite reinforcement to the solutions. The tensile strengths of the unreinforced polymers were measured from approximately 16 to $32 \mathrm{MPa}$, and with reinforcement the tensile strength increased. The tensile strengths of the OWFs are also in the same range for some of the most commonly used polymers, such as low density polyethylene (LDPE), high density polyethylene (HDPE), polytetrafluorethylene (PTFE), polypropylene (PP), and polystyrene (PS) [16]. A comparison is shown in Figure 3. Elongation however of the same commodity plastics (LDPE 100-650\%; HDPE 10-1200\%; PTFE $200-400 \%$; PP $100-600 \%)$ is much higher than of OWF, except for PS (1.2-2.5\%) [16].

3.4. Thermal Characteristics of Orange Waste Films. The results of the thermogravimetric analysis are represented as Table 2 and Figure 4 . In both drying cases, the trend was similar, and thermal degradation consisted of three stages. The first thermal event was a weight loss up to $3.79-3.94 \%$ at an average temperature of $80.38-80.61^{\circ} \mathrm{C}$ due to the evaporation of water in the samples. This could be explained by biopolymers and glycerol being hygroscopic substances, and moisture content is dependent on the ambient conditions. The second thermal event occurred at a maximum temperature of $251.89-253.20^{\circ} \mathrm{C}$, and the decomposition ratio was $28.54-29.28 \%$, which was related to the depolymerisation of the pectin present in the films [23]. The third thermal event was observed at a maximum temperature of $351.89-354.34^{\circ} \mathrm{C}$; the decomposition of the films showed a further $24.10-25.15 \%$ that could be referred to the decomposition of the cellulose [24]. The remaining $21.97-23.20 \%$ of the films after thermal treatment is ash. 
TABLE 2: TGA thermogram showing decomposition rate of the OWFs: moisture loss, decomposition ratio 1, decomposition ratio 2 and residue and the maximum temperatures related to the thermal events.

\begin{tabular}{lccccccc}
\hline Sample & Moist. loss $(\%)$ & MLT $\left({ }^{\circ} \mathrm{C}\right)$ & D1 ratio $(\%)$ & DT 1 $\left({ }^{\circ} \mathrm{C}\right)$ & D2 ratio $(\%)$ & DT 2 $\left({ }^{\circ} \mathrm{C}\right)$ & Residue $(\%)$ \\
\hline OD 1 & 4,07 & 81,44 & 27,65 & 252,58 & 25,63 & 351,5 & 24,66 \\
OD 2 & 3,94 & 78,90 & 26,77 & 252,6 & 26,7 & 350,27 & 35,03 \\
OD 3 & 3,82 & 81,49 & 33,43 & 250,5 & 23,12 & 22,22 \\
Average & 3,94 & 80,61 & 29,28 & 251,89 & 25,15 & 351,89 & 21,97 \\
St. dev. & 0,13 & 1,48 & 3,62 & 1,21 & 1,84 & 2,85 \\
\hline ID 1 & 3,50 & 84,83 & 29,07 & 252,37 & 22,68 & 352,7 & 24,58 \\
ID 2 & 3,87 & 79,93 & 29,31 & 254,09 & 24,96 & 246 & 20,97 \\
ID 3 & 4,02 & 76,38 & 27,25 & 253,14 & 24,66 & 354,31 & 24,05 \\
Average & 3,79 & 80,38 & 28,54 & 253,20 & 24,10 & 354,34 & 23,20 \\
St. dev. & 0,26 & 4,24 & 1,13 & 0,86 & 1,24 & 1,65 & 1,95 \\
\hline
\end{tabular}

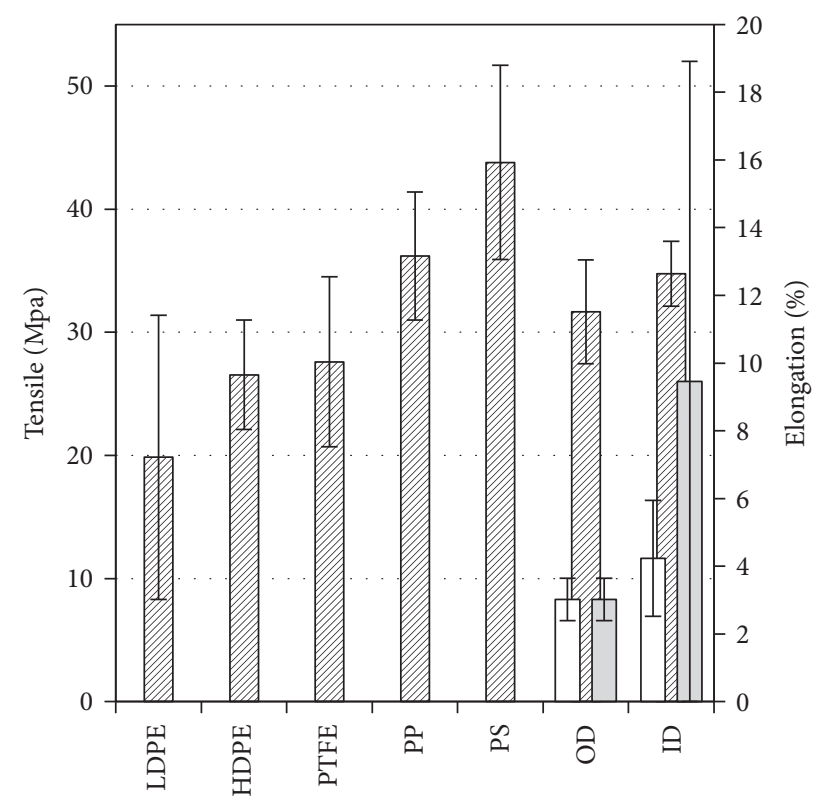

FIGURE 3: Left axis: tensile strength of different commodity plastics [16] and tensile strength at maximum load of OD and ID films are shown; right axis: elongation at maximum tensile strength (white bars) and elongation at break (grey bars) belonging to OD and ID films are shown (elongation at break of commodity plastics is not shown in the image due to the great difference of values).

The films were also analysed using differential scanning calorimetry (Figure 5) to determine glass transition temperature (Tg). An endothermic transition was detected around 83.29 and $88.12^{\circ} \mathrm{C}$, with an onset temperature of 61.21 and $66.22^{\circ} \mathrm{C}$ during the first scanning of the ID and OD samples, respectively. After the rescanning of the samples, the endothermic transition disappeared. Aguilera et al. [25] also reported that endothermic curves of biopolymers had disappeared after rescanning the samples and thus there was no $\mathrm{Tg}$ observed. As there was no Tg observed in the thermograms of OWFs, there was no melting point either. It is then assumed that the OWFs have less crystals present and they are mostly amorphous.

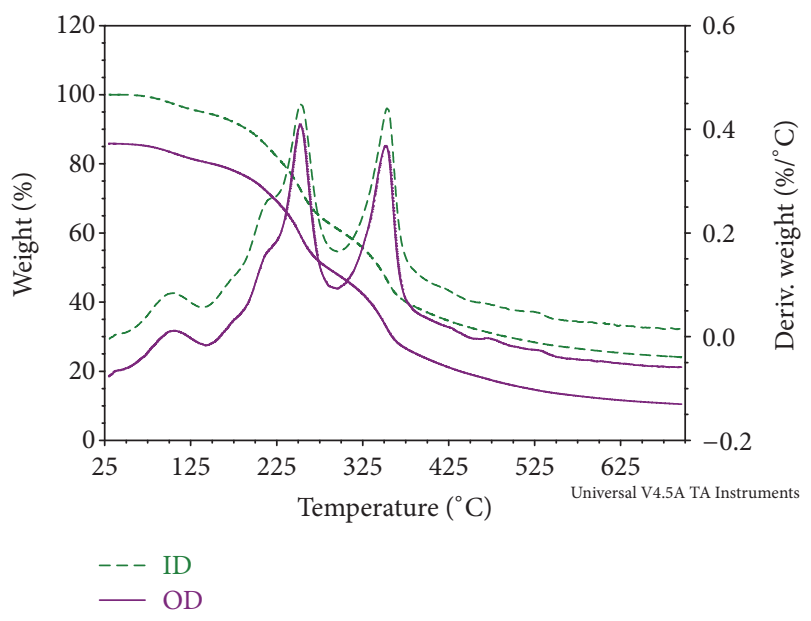

FIGURE 4: TGA thermogram showing weight loss curves and derivative weight curves of OD and ID films.

DMTA characterization was carried out in order to compensate DSC analysis and to monitor the temperature dependence of the storage modulus, $\tan \delta$, and the loss modulus. The results are shown in Figures 6 and 7. The storage modulus (Figure 6) is a measurement of the stiffness of the material, and both ID and OD films showed similar behaviours. The sample OD had a storage modulus of $1.4 \mathrm{GPa}$ at $10^{\circ} \mathrm{C}$. As the temperature rose, there was a clear decrease of the storage modulus. At $70^{\circ} \mathrm{C}$, the storage modulus decreased to $0.6 \mathrm{GPa}$. In other words, the sample showed a more elastic behaviour at higher temperatures and a more plastic behaviour (storing energy rather than returning it) at low temperatures, which is a typical characteristic of polymers. The other sample, ID, had a storage modulus of $1.0 \mathrm{GPa}$ at $10^{\circ} \mathrm{C}$ and $0.4 \mathrm{GPa}$ at $70^{\circ} \mathrm{C}$. While OD generally had a somewhat higher storage modulus, the difference between the two samples was not significant. The temperature dependence of $\tan \delta$ can be seen in the same figure. Under the chosen test conditions, $\tan \delta$ continuously increased with the increasing temperature. For the sample $\mathrm{OD}$, a weak transition could be seen at $98^{\circ} \mathrm{C}$. For ID, no clear transition was observed. 


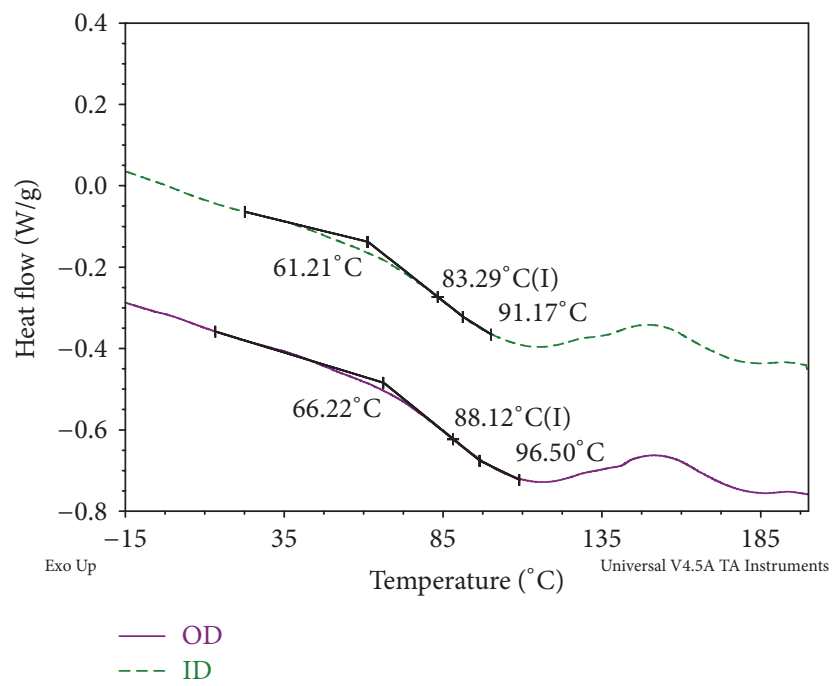

FIGURE 5: DSC analyses showing an endothermic transition of OD and ID films.

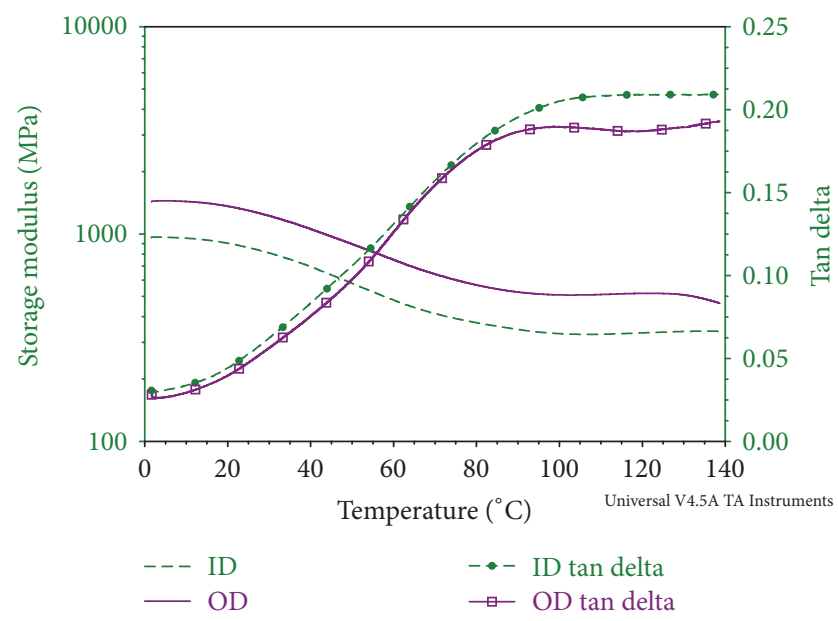

FIGURE 6: Storage modulus and $\tan \delta$ are shown of OD and ID films.

The loss modulus describes the viscous properties of the material (Figure 7). As mentioned in the DSC analysis, there was no obvious glass transition in the DSC curve. The reason the loss modulus curve does not show a maximum could be the same why no Tg was observed in the DSC curve. For the sample OD, loss modulus increased continuously and reached a maximum at $76^{\circ} \mathrm{C}$. Again, for ID, the transition could not be seen so clearly.

3.5. Antimicrobial Activity of Orange Waste Films. Dlimonene, the major component of orange oil, is in turn well-known for its protecting behaviour against pathogens [26]; thus it would indicate an antimicrobial property of the films. However, the results obtained from the optical density measurements and glucose consumption, showed that films did not have antimicrobial property. In both cases, the length of the lag phase and the exponential phase of the

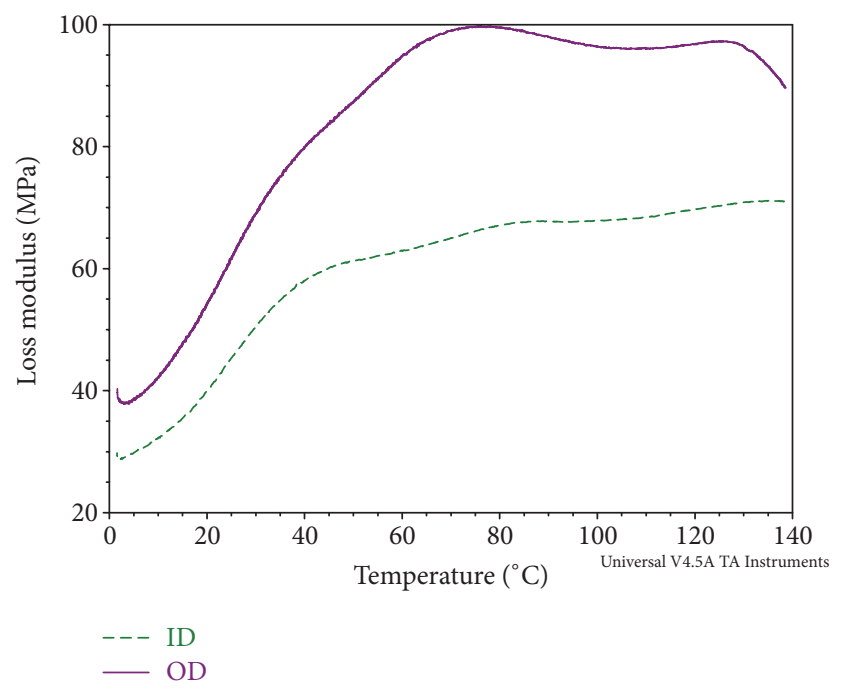

FIGURE 7: DMTA thermogram is showing the loss modulus of OD and ID films.

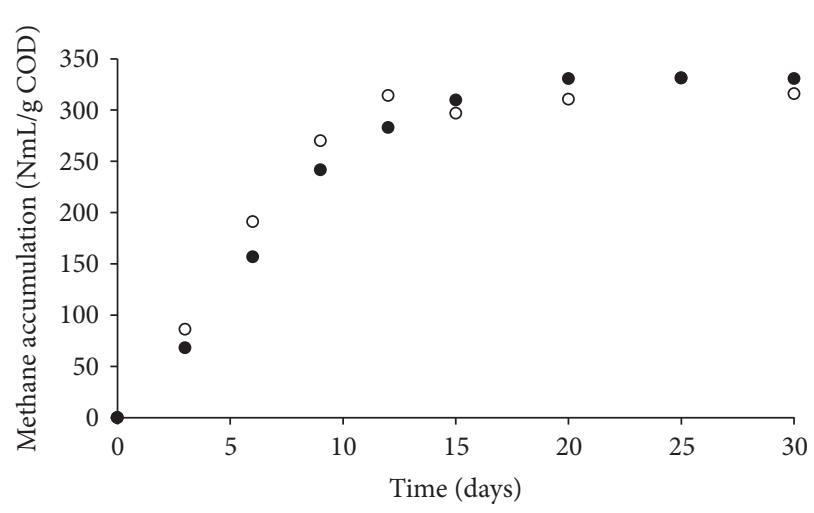

FIGURE 8: Anaerobic degradation of OD (full circles) and ID (empty circles) films, expressed in the accumulation of methane gas/g COD over a period of 30 days at $55^{\circ} \mathrm{C}$.

microorganisms were the same for blanks and for the samples containing the films. One reason could be that orange oils were removed during the sugar removal pretreatment step, which was similarly performed as the cold pressing method, a preferred method for extracting essential oils from citrus fruits [27], and is usually done by soaking the citrus fruit in warm water and pressing the rind with a sponge to collect the oil.

3.6. Biodegradability of Orange Waste Films. Biodegradability is a key feature of next generation plastics and the European Committee for Standardization specifies a 90\% degradation within six months [28]. In the anaerobic degradation study, films reached $90 \%$ degradation in about 15 days (Table 3 ). Figure 8 shows the methane accumulation based on the theoretical maximum $(350 \mathrm{NmL} / \mathrm{g} \mathrm{COD})$ of a substance by measuring the COD. 
TABLE 3: Degradation (\%) of ID and OD films (results based on average) by days.

\begin{tabular}{lcccccccc}
\hline Deg. time $(\mathrm{d})$ & 3 & 6 & 9 & 12 & 15 & 20 & 25 & 30 \\
\hline ID & 25 & 55 & 77 & 90 & 85 & 89 & 95 & 90 \\
OD & 20 & 69 & 81 & 89 & 95 & 95 & 95 & 94 \\
\hline
\end{tabular}

\section{Conclusions}

The biofilms made from orange waste show similar physical properties as do some of the commodity plastics. It was observed that the drying method did not make a difference for mechanical and thermal properties of the films but resulted in a more uniform surface. The films were also biodegradable under anaerobic conditions. The main constituents of the biofilms, pectin and cellulosic fibres, suggest an application where biodegradability is as important as strength, such as a short-lived packaging material. Generally, the properties are promising, although further characterization and improvements are necessary in order to achieve the desired features, less hygroscopic characteristics, for example. Finally, production of biofilms from orange waste not only opens up opportunities for the production of environmentally friendly biomaterials but also could be a solution for the challenges arisen upon disposal of orange waste.

\section{Conflicts of Interest}

The authors declare no conflicts of interest regarding the publication of this article.

\section{Acknowledgments}

The authors would like to express their gratitude to ÅForsk Foundation for financial support and to Brämhults Juice $\mathrm{AB}$ for the raw material. The authors are also grateful for the technical help received from Lukitawesa, Ilona Sárvári Horváth, Ramkumar B. Nair, and Jorge A. Ferreira and from Christine Räisänen for feedback on the structure and language.

\section{References}

[1] Statista, Global plastic production from 1950 to 2015 (in million metric tons), Statista, 2016.

[2] E. Bioplastics, "Biobased plastics - Fostering a resource efficient circular economy; Benefits, feedstock types, sustainable sourcing, land use," in Proceedings of the in 10th European Bioplastics Conference, Berlin, Germany: European Bioplastics, 2015.

[3] A. M. Balu, V. Budarin, P. S. Shuttleworth et al., "Valorisation of orange peel residues: Waste to biochemicals and nanoporous materials," ChemSusChem, vol. 5, no. 9, pp. 1694-1697, 2012.

[4] M. Boukroufa, C. Boutekedjiret, L. Petigny, N. Rakotomanomana, and F. Chemat, "Bio-refinery of orange peels waste: A new concept based on integrated green and solvent free extraction processes using ultrasound and microwave techniques to obtain essential oil, polyphenols and pectin," Ultrasonics Sonochemistry, vol. 24, pp. 72-79, 2015.
[5] USDA, Citrus: World Markets and Trades, United States Department of Agriculture Foreign Agricultural Service, USA, 2016.

[6] J. Ángel Siles López, Q. Li, and I. P. Thompson, "Biorefinery of waste orange peel," Critical Reviews in Biotechnology, vol. 30, no. 1, pp. 63-69, 2010.

[7] F. R. Marín, C. Soler-Rivas, O. Benavente-García, J. Castillo, and J. A. Pérez-Alvarez, "By-products from different citrus processes as a source of customized functional fibres," Food Chemistry, vol. 100, no. 2, pp. 736-741, 2007.

[8] K. Rezzadori, S. Benedetti, and E. R. Amante, "Proposals for the residues recovery: Orange waste as raw material for new products," Food and Bioproducts Processing, vol. 90, no. 4, pp. 606-614, 2012.

[9] R. U. Abass, "Mechanical behaviour of natural material (orange peel) reinforced polyester composite," International Journal of Engineering Sciences Research Technology, vol. 4, no. 3, pp. 166172, 2015.

[10] V. S. Aigbodion, C. U. Atuanya, E. A. Igogori, and P. Ihom, "Development of High-Density Polyethylene /Orange Peels Particulate Bio-Composite," Gazi University Journal of Science, vol. 26, no. 1, pp. 107-117, 2013.

[11] N. Hall, "Bioplastics made from coffee and orange?" 3D Printing Industry, 2016.

[12] V. Bátori, D. Åkesson, A. Zamani, and M. J. Taherzadeh, "Pectin based composites," in Handbook of composites from renewable materials, M. K. Thakur, M. R. Kessler, and V. K. Thakur, Eds., pp. 487-517, John Wiley \& Sons Inc, 2016.

[13] F. Ansari, M. Skrifvars, and L. Berglund, "Nanostructured biocomposites based on unsaturated polyester resin and a cellulose nanofiber network," Composites Science and Technology, vol. 117, pp. 298-306, 2015.

[14] N. Ninan, M. Muthiah, I.-K. Park, A. Elain, S. Thomas, and Y. Grohens, "Pectin/carboxymethyl cellulose/microfibrillated cellulose composite scaffolds for tissue engineering," Carbohydrate Polymers, vol. 98, no. 1, pp. 877-885, 2013.

[15] W.-X. Yu, Z.-W. Wang, C.-Y. Hu, and L. Wang, "Properties of low methoxyl pectin-carboxymethyl cellulose based on montmorillonite nanocomposite films," International Journal of Food Science \& Technology, vol. 49, no. 12, pp. 2592-2601, 2014.

[16] J. W. D. Callister, Materials science and engineering: an introduction, John Wiley \& Sons, Inc., USA, 2007.

[17] A. Sluiter, B. Hames, R. Ruiz et al., "Determination of Structural Carbohydrates and Ligning in Biomass," Technical Report NREL/TP-510-42618, Golden, Colorado, USA, 2008.

[18] P. Srivastava and R. Malviya, "Extraction, characterization and evaluation of orange peel waste derived pectin as a pharmaceutical excipient," Natural Products Journal, vol. 1, no. 1, pp. 65-70, 2011.

[19] T. Í. S. Oliveira, M. F. Rosa, F. L. Cavalcante et al., "Optimization of pectin extraction from banana peels with citric acid by using response surface methodology," Food Chemistry, vol. 198, pp. 113-118, 2016.

[20] B. Rivas, A. Torrado, P. Torre, A. Converti, and J. M. Domínguez, "Submerged citric acid fermentation on orange peel autohydrolysate," Journal of Agricultural and Food Chemistry, vol. 56, no. 7, pp. 2380-2387, 2008.

[21] T. L. Hansen, J. E. Schmidt, I. Angelidaki et al., "Method for determination of methane potentials of solid organic waste," Waste Management, vol. 24, no. 4, pp. 393-400, 2004.

[22] A. F. Routh, "Drying of thin colloidal films," Reports on Progress in Physics, vol. 76, no. 4, pp. 46603-46632, 2013. 
[23] A. Ghaffari, K. Navaee, M. Oskoui, K. Bayati, and M. RafieeTehrani, "Preparation and characterization of free mixed-film of pectin/chitosan/Eudragit ${ }^{\circledR}$ RS intended for sigmoidal drug delivery," European Journal of Pharmaceutics and Biopharmaceutics, vol. 67, no. 1, pp. 175-186, 2007.

[24] M. Semsarilar, J. Tom, V. Ladmiral, and S. Perrier, "Supramolecular hybrids of cellulose and synthetic polymers," Polymer Chemistry, vol. 3, no. 12, pp. 3266-3275, 2012.

[25] J. M. Aguilera, T. R. Cuadros, and J. M. Del Valle, "Differential scanning calorimetry of low-moisture apple products," Carbohydrate Polymers, vol. 37, no. 1, pp. 79-86, 1998.

[26] G. Forgács, M. Pourbafrani, C. Niklasson, M. J. Taherzadeh, and I. S. Horváth, "Methane production from citrus wastes: process development and cost estimation," Journal of Chemical Technology \& Biotechnology, vol. 87, no. 2, pp. 250-255, 2012.

[27] M. A. Ferhat, B. Y. Meklati, and F. Chemat, "Comparison of different isolation methods of essential oil from Citrus fruits: cold pressing, hydrodistillation and microwave 'dry' distillation," Flavour and Fragrance Journal, vol. 22, no. 6, pp. 494-504, 2007.

[28] A. Soroudi and I. Jakubowicz, "Recycling of bioplastics, their blends and biocomposites: A review," European Polymer Journal, vol. 49, no. 10, pp. 2839-2858, 2013. 

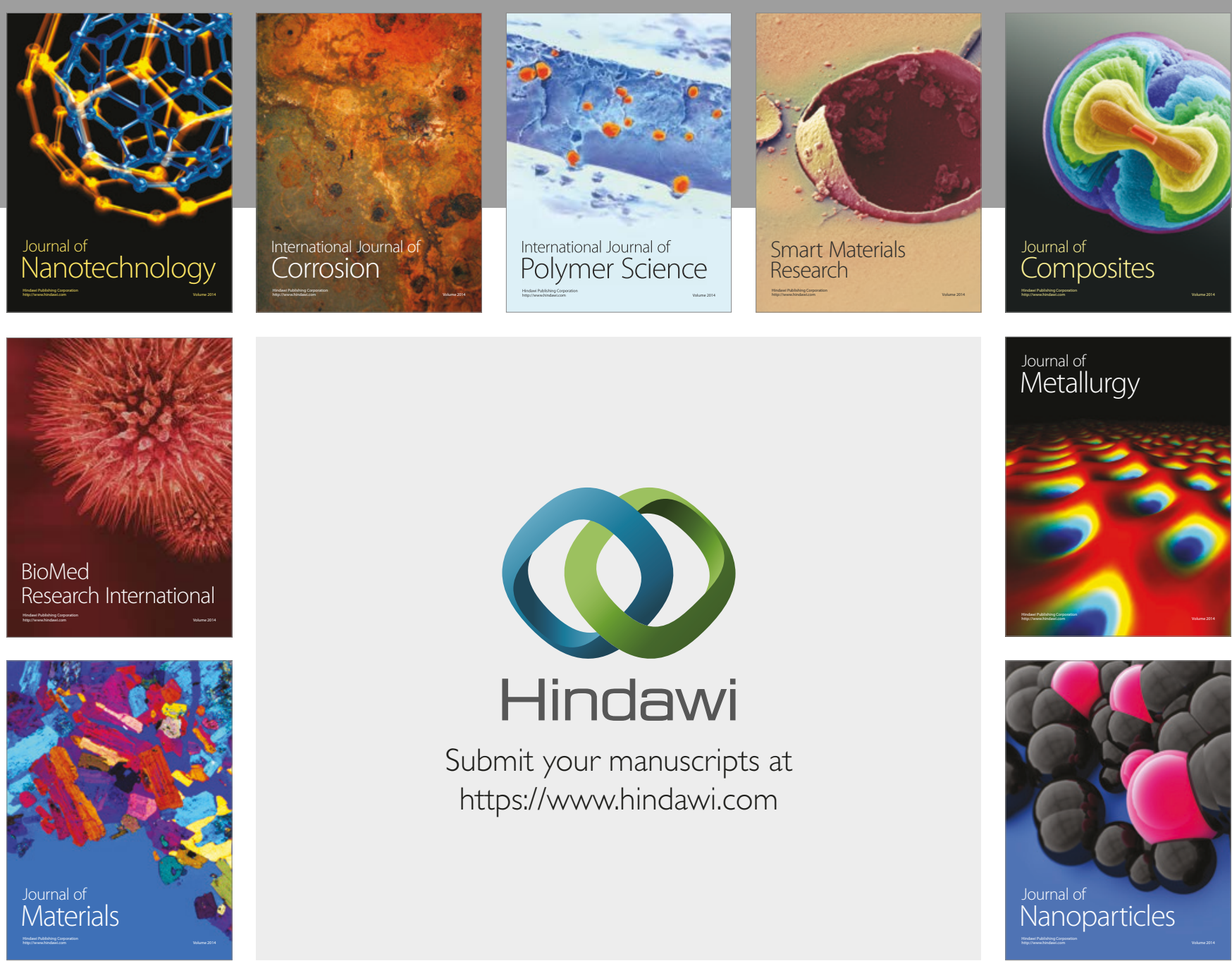

\section{Hindawi}

Submit your manuscripts at

https://www.hindawi.com
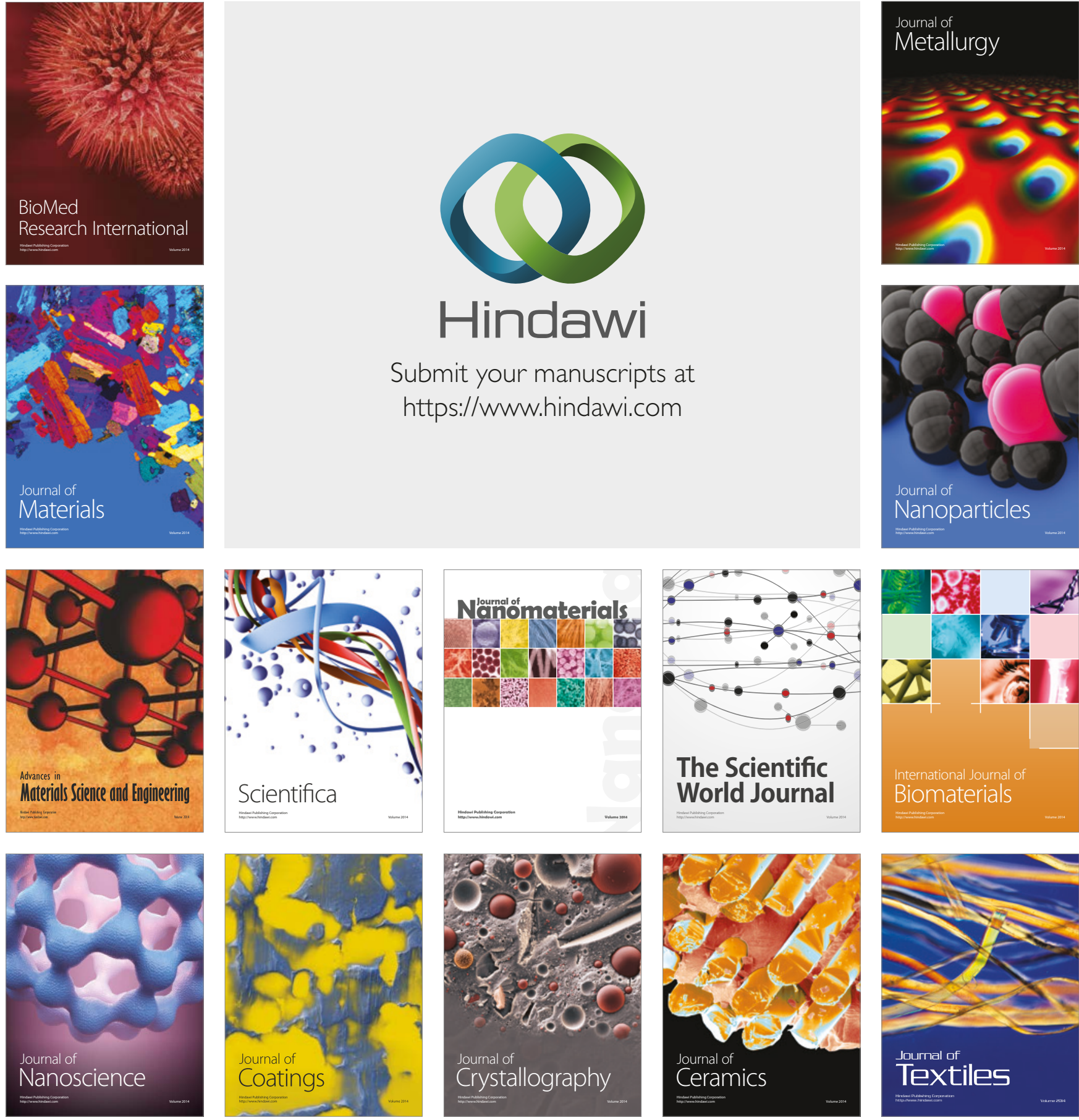

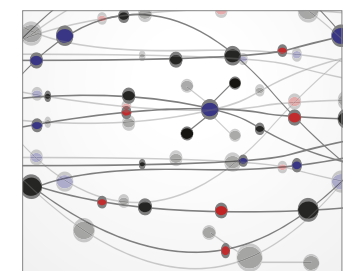

The Scientific World Journal
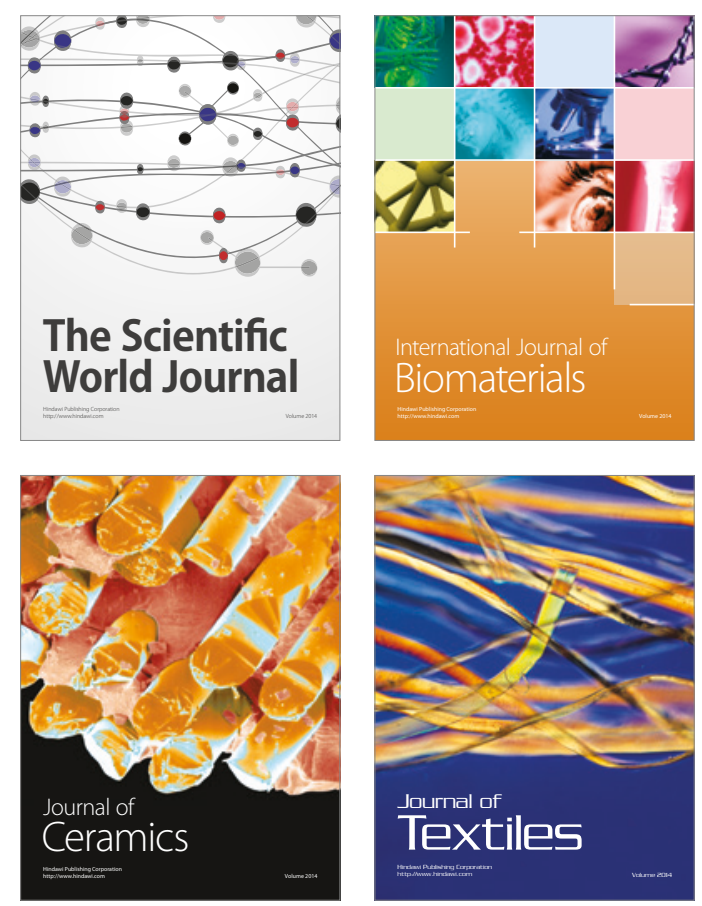